Volume 9, No.1.1, 2020

International Journal of Advanced Trends in Computer Science and Engineering

Available Online at http://www.warse.org/IJATCSE/static/pdf/file/ijatcse4791.12020.pdf

https://doi.org/10.30534/ijatcse/2020/4791.12020

\title{
Development Of Wireless Power Transfer Using Electromagnetic for Mouse Application
}

\author{
Chia Chao Kang \\ Facilities Maintenance Engineering, Universiti Kuala Lumpur (MITEC), Masai, Johor, Malaysia.
}

\begin{abstract}
Wireless Power Transfer (WPT) in simple terms is the transferring of power (electrical power) from one source of power to the electrical load without using any type of so-called interconnection. WPT can be said as a system of transferring electrical power through the air. The basic component used in WPT is the primary coil and secondary coil by using the induction theory. Where, DC voltage will invert into AC voltage by using inverter circuit. Then, it will flow in the primary coil and induce amount of AC voltage in the secondary coil through the electromagnetic field between both coils. The AC voltage then can be used to power up a wireless computer mouse after converting the $\mathrm{AC}$ to $\mathrm{DC}$ voltage using bridge rectifier. Most of the commercialized wireless computer mouse are powered up by the batteries and bring up a few problems. The utilization of battery can increase electronic waste issue and can be harmful to the health and environment. Therefore, this problem is overcome by this project. The objectives of this project are to analyze the performance efficiency of the development prototype and to develop a wireless power transfer prototype using electromagnetic for mouse application. In this project, inductive power transfer method is suggested and focused on. This method enables wireless power transmission from laptop to wireless computer mouse. Means that, the wireless mouse still can be powered up even though the battery was eliminated. This project also provide more useful and effective especially for right handed user and towards green technology without battery.
\end{abstract}

Key words: Wireless power transfer, Inductive power transfer, Electromagnetic field, Electronic waste.

\section{INTRODUCTION}

Wireless Power Transfer (WPT) can be defined as a mechanism of alteration power from the power supply to the load or device without connects the wire through an air gap. A power from an AC source to the adaptable battery or accessory can be provided by WPT without interconnecting wires. Besides, WPT also can recharge cars, hand phones and home appliances. The concept of WPT was first introduced by Nikola Tesla in 1893. Mohamed M. El Rayers stated that, the concept of converting power without wires has been introduced by Nikola Tesla which capable to illuminate the bulbs without wire by using electrodynamic induction at his Colorado Springs Lab [1].

WPT can be divided into four types used to transmit the power, which are acoustic power transfer, light power transfer, inductive power transfer and capacitive power transfer. For acoustic power transfer, the ultrasonic or vibration propagation wave can be optimized as compared to electromagnetic fields for power transmission because it is comparatively new. Next, a huge amount of power was able to supply by light power transfer and it can influenced their efficiency by its emission losses over a immense distance. Besides, for capacitive power transfer use plates to generate and receive a changing electric field but for the inductive power transfer usually use coils to generate and receive a changing magnetic field. The study by [2] concludes the power is transferred via induction between two magnetically coupled coils.

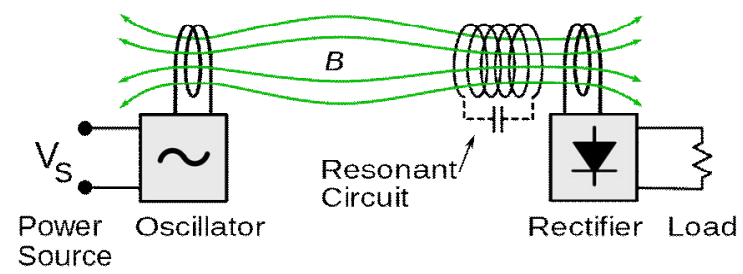

Figure 1: Mechanism of Inductive Coupling

Figure 1 shows how the inductive coupling functions. The magnetic field was transmitted the power between the two coils which are transmitter and receiver coil. The transformer was form together by a transmitter and receiver coils. Oscillating magnetic field (B) was created by an AC source through the primary coil that is transmitter. The magnetic field flow to the secondary coil of receiver, where it will induce an Electromotive Force (EMF) that generates an alternating current on the receiver. To drive the load, it either be rectified to DC current by a rectifier or the induced alternating current (AC) drive the load straight forward in the receiver.

In new technology, the wireless charger is available which apply the Inductive Power Transfer (IPT) approach to 
recharge devices such as hand phone. Thus, in this project, a wireless mouse is suggested because it is uses IPT same as wireless charger application. Other than that, a battery-less wireless mouse is suggested and will be developed based on the IPT concept. Means that the battery will eliminate from the computer mouse and yet it still can be powered up. Therefore, the aim of this project is to develop wireless power transfer using electromagnetic for mouse application. This project also to provide more useful and effective without battery towards green technology. In addition, these projects develop especially for right handed user.

\section{LITERATURE REVIEW}

\subsection{History in Wireless Power Transfer}

An early 1891, the idea of wireless power transmission was ponder by the Nikola Tesla and was demonstrated "the transmission of electrical energy without wires" which based on electrical conductivity [3]. Nikola Tesla was collaborated with Heinrich Hertz to make a theory about the possibility of power transmitted wirelessly. Nikola Tesla is one of the person who developed radio and is referred to as "Farther of Wireless"[4]. In 1893, the lighting of electrical bulbs wirelessly for power transmission was manifested by Tesla at the Chicago World's Columbian Exposition.

The Wardenclyffe tower shown in Figure 2 that have been invented and created by the Nikola Tesla primarily for wireless power transfer compared to telegraphy [5] resulted the first idea of broadcasting system in the world. Tesla idea basically wanted to transfer electricity from Wardenclyffe tower to the whole globe without using the ionosphere. Unfortunately, the power transfer efficiency was significantly decreased due to large electric fields and at the same time Tesla's invention was not successful [6].

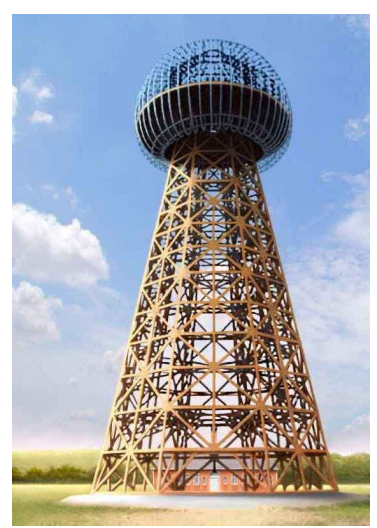

Figure 2: Wardenclyffe tower (Tesla tower)

The Wireless Power Transfer (WPT) system is the transferring of power source without using of wires. Research found that wireless power transfer is unique as to associate the devices to a source of power; it does not used of any type of wiring [7]. WPT is effective to powered up electrical devices where connect to the wires are unwieldy and risky. A researche stated that to convey the electric power, the wireless electric power transmission is one of the methods from source to destination which is load [8]. Next, WPT is much productive and cost of the transmission is low because it does not use a lot of wires. This statement supported by other researcher which is Mohammad Shidujaman, he point out that wireless power transfer gives an profitable, quick and maintenance cost is low as contrast to previous technologies [9]. To transmit the electricity over a wireless intermediate, there are three methods or approaches are used such as short range, mid range and long range.

\subsection{Short Range}

This range takes only a few centimeters. For example is transformer which good for a short length wireless power transfer based on the inductive coupling technique. The electricity was transferred by the transformer as an electromagnetic field. Arjun Sharma analyzed that the electromagnetic field will produces at the inside and outside of the coils when the current pass through the coils and form a strong and weak field [8]. For strong field, the magnetic field is produced inside the coil and for weak field; the magnetic field is produced around the coil. For transferring the electric power, the two coils are used which are primary coil that directly attached to the source of power and for the secondary coil it gain electricity to powered up the load or device. In between primary coil and secondary coil, an electromagnetic flux is created.

\subsection{Mid Range}

Based on Arjun Sharma, he stated that there are three approached used in mid range of wireless electric power transmission which are resonant inductive coupling, inductive coupling, and air ionization [8]. Inductive resonant is the consolidation between inductance and resonant that used to transmit electricity at the given range with safety and efficiently. As argued by [7], this technology was competent to transmit power effectively, harmlessly and farther distance can improve the device. Resonant can be function as to form a stable reaction between the primary coil and secondary coil. Other than that, inducing the magnetic flux between the two coils is one of the functions of inductance.

\subsection{Long Range}

Another researcher revealed his study that laser power transmission, microwave power transmission and solar power satellite are some of the approaches for transmitting 
electricity through the long distance [8]. For the microwave power transmission, it is the most used among others to transmit the electricity from power source to long distance destination.

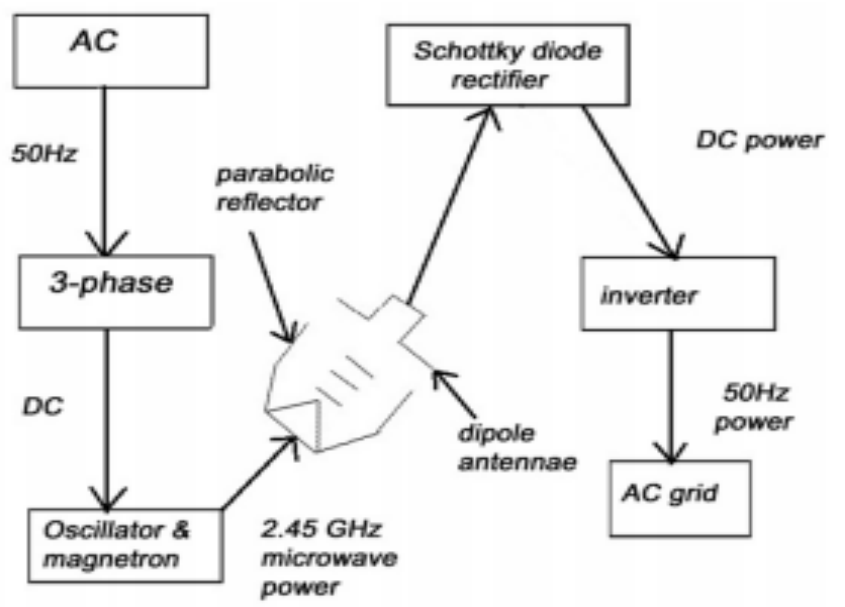

Figure 3: Construction of Microwave Power Transmission

Based on Figure 3, the microwave energy was converted from the electrical energy and it will transmit via the antenna. Then, the electrical energy was converted from the microwave signal at the destination side. The AC signal in must be convert to the DC signal so that the electrical power can convert to the microwave signal. After that, at receiver side, the DC signal is converted into AC signal.

\subsection{Inductive Power Transfer}

After that, at receiver side, the DC signal is converted into AC signal. Wireless power transfer (WPT) is basically applying the inductive coupling to transfer the power between transmitter coil and receiver coil. It is known as Inductive Power Transfer (IPT) or 'near-field transfer' [10]. In the IPT system, the AC voltage will flow through the power inverter then to the power compensation. The primary resonance coil will then works as the input voltage to supply a wireless power transfer to the receiver unit. The IPT act as the antenna and flow to the bridge rectifier to switch an AC voltage to the DC voltage. In order to have electric current induced by the magnetic field, a receiver coil should be aligned with the transmitter coil at a given distance [11]. Then the power which is DC voltage will be supplied to the load $[12,13]$. Figure 4 indicates the schematic of IPT system.

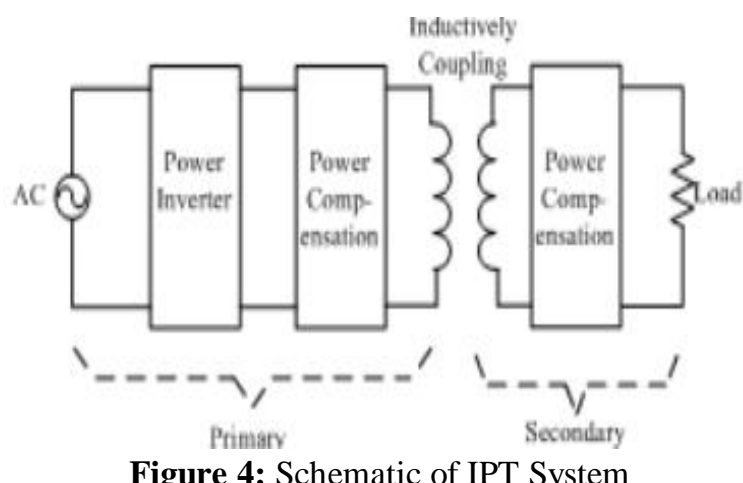

\subsection{Qi Wireless Charger Application}

Qi wireless charging because it is a global standard and more efficient when used it. By simply placing the smartphones on top of a wireless pad, it allows user to wirelessly charge a compatible devices battery using induction transfer. This is because the type of connector which is micro USB wire is the traditional way to charge the smart phones [14]. To overcome this problem, the Qi wireless charging is a best solution.

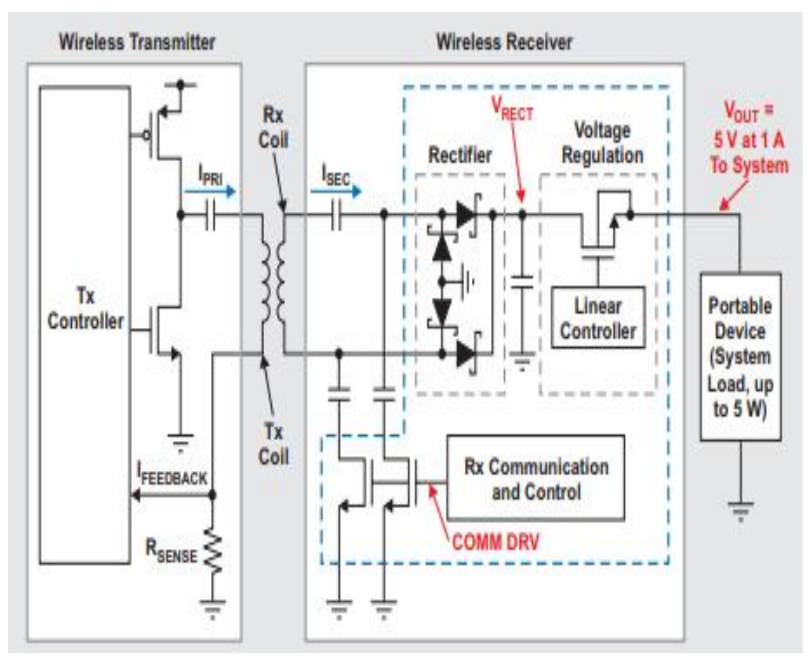

Figure 5: Block diagram of a Qi-compliant system

From Figure 5 WPT has a receiver in the portable device which supplied energy to charge the battery. The transmitter is placed in a rigid base and connected to the power supply. When input power flow to the transmitter, it will convert to AC then magnetically coupled from the transmitter coil to the receiver coil when both of the coils were closed to each other. In recent researcher, he indicated that it have two separate physical devices that consist in the Qi-compliant system which are transmitter and receiver [15]. When both of them are in close proximity, it will form a coupled inductor relationship.

For the output from the receiver generally $5 \mathrm{~V}$ at $1 \mathrm{~A}$ that gives input power to the battery charger inside the devices. 
Next, the receiver chip can controlled the transmitter operation in this system by using feedback in the form of digital communication packets sent back over the same magnetic coupling path. Other than that, to send information in data packets across the two coils, the Qi-compliant receiver communicates with transmitter by using load modulation. The transmitter is adjusted at a $2 \mathrm{kHz}$ rate which interpreted by the transmitter and used for control. Several types of packets can be sent by the receiver to the transmitter for information and control purposes.

\subsection{Multiple Resonators of Wireless Power Transfer System}

A power transfer can be carried by the WPT based on the multiple resonators (multi-resonator) for a wide range more than the resonant objects diameter. It also can control high power load and transmission efficiency if this system planned correctly. This is the way to increase the efficiency of the WPT but it is quite challenge in this field. The power transfer would be efficient at minor coupling coefficient that permitted by the strong coupled multiple resonator WPT system and can farther distances as opposed to the conventional magnetic coupling WPT system.

The magnetic resonance coupling WPT system has been done by many researchers since 2007 [16]. To analyze this system, it has two methods which are Equivalent Circuit Method (EQC) and Coupled Mode Theory (CMT) that have been a handy tool to examine resonators since 1950's. One of the researchers studied the WPT to power multiple resonators. Based on his research, the four magnetically-coupled resonators were proposed to the WPT system as shown in Figure 6 [17].

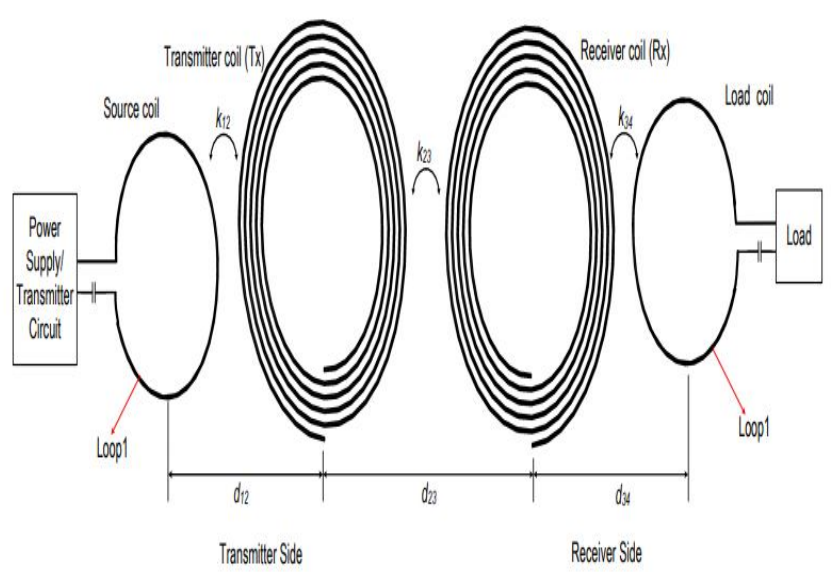

Figure 6: Magnetic resonance-coupled wireless power transfer

The power supply is powered up the source coil then transmitted to the transmitter coil. At this side is called transmitter. After that, the transmitter coil alters the energy to the receiver coil that is magnetically coupled to each other. For the receiver side, the receiver coil transfer the energy to the load coil and then supplied to the load. Other than that, the efficiency of the power transfer for this system is depend on the distance between transmitter and receiver which is $\mathrm{d} 23$ and to obtain maximum efficiency, it must have an optimum distance. As supported by Sample, the drive loop and transmitter coil was built into a single device that is k12 must be fixed and similarly to the $\mathrm{k} 34$ must also be fixed [18]. Hence, $\mathrm{k} 23$ alter as a purpose to set the distance between the transmitters to the receiver as demonstrated in the Figure 7. Hui also mentioned that, in order to escalate efficiency of WPT system, it should minimize the coefficient of mutual coupling between transmitter coil and receiver coil [19].

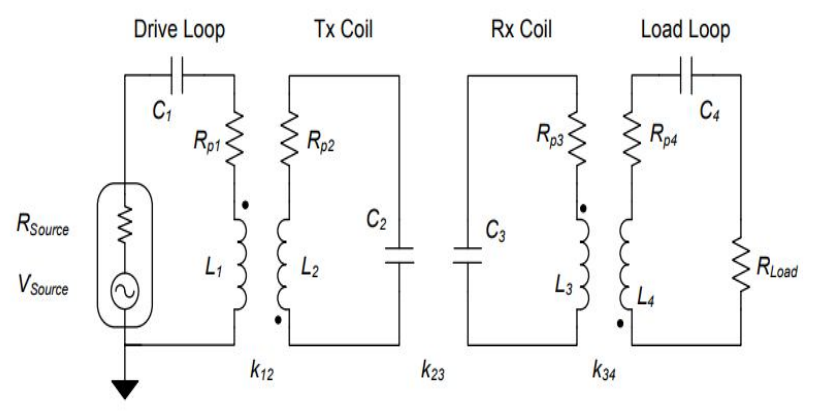

Figure 7: Equivalent circuit of WPT system

\section{METHODOLOGY}

The method that is implemented for this project is WPT system by using IPT concept. In order to give a clear overview on how the WPT system designed, the block diagram was performed by refers to Figure 8. The block diagram have 6 major parts that present in the WPT system using inductive coupling which are power supply, inverter circuit, transmitter coil, receiver coil, rectifier circuit and electrical load.

The main DC power supply supplied from the USB port laptop, then connect to the inverter for inverting DC into AC voltage. The primary coil will then works as the input voltage to supply a WPT to the receiver unit. At the receiver part, the rectifier functions as to convert the AC voltage to the DC voltage which supplied energy to power up the wireless mouse. The study by Ko et al. stated that the power output from the power supply is amplified and used to drive a primary coil [20]. The transmitted power was picked up by the secondary coil then receiver part convert AC to DC supply for powering up the load. The inverter and rectifier play an important role so that the wireless mouse gets the power supply to power up as shown in Figure 9.

Basically, an inverter is an electronic device that capable of transforming a direct current into an alternating current at a given voltage and frequency. Inverters are used for many applications, as in this project where a DC voltage from the USB port laptop must be converted so that the primary coil can supply an $\mathrm{AC}$ voltage in the form of sinusoidal wave. 
According to Harrison, the transmitting coil has been applied by an $\mathrm{AC}$ voltage of amplitude, $\mathrm{V}_{\mathrm{T}}$ and it will induced an $\mathrm{AC}$ voltage, $V_{R}$ at the receiving coil then the electrical load is connected to the receiving coil [21]. In addition, a rectifier is an electrical device which converts from AC voltage to the DC voltage that flows in one direction only. From this project, it used the full-wave rectification. The whole of the input was converted by the full-wave rectifier to the constant polarity either positive or negative at the output. Besides, the both polarities of the input waveform were converted by the full-wave rectification to pulsating direct current (DC) and yield a higher mean output voltage.

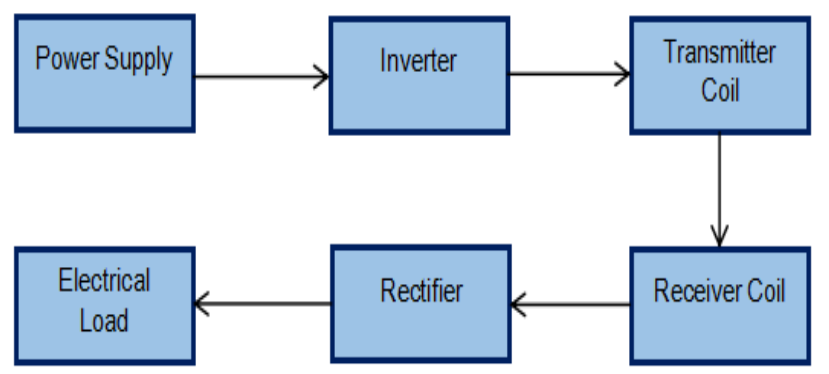

Figure 8: Block diagram of WPT system using IPT concept

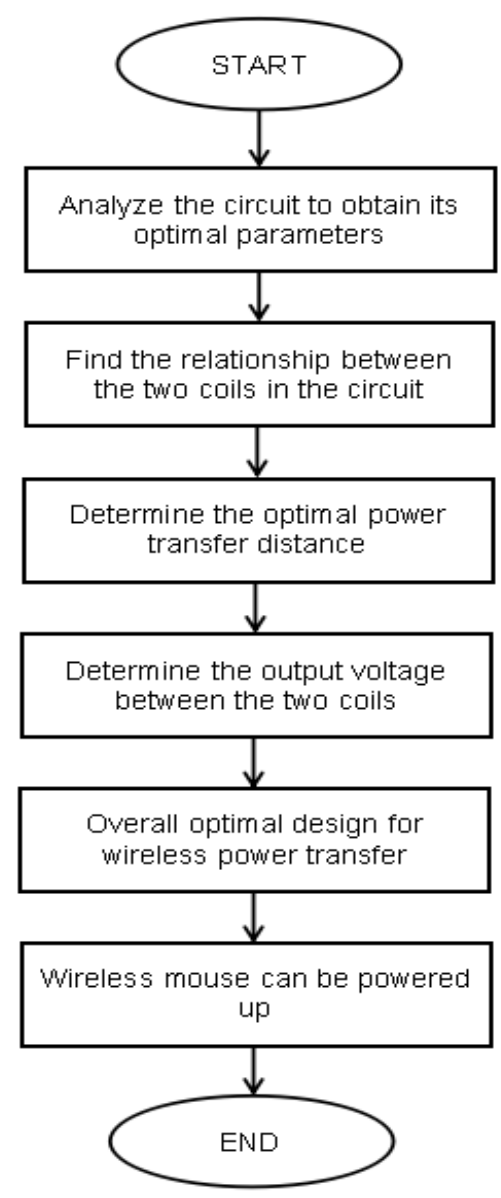

Figure 9: Flowchart
In order to complete this experiment, firstly, electronic circuit for inverter and rectifier circuit should be design to indicate the functioning of the WPT for mouse application so that it can meet the requirement. The electronic equipment used is transistor, resistor, diode, capacitor, electrical wire and printed circuit board (PCB).
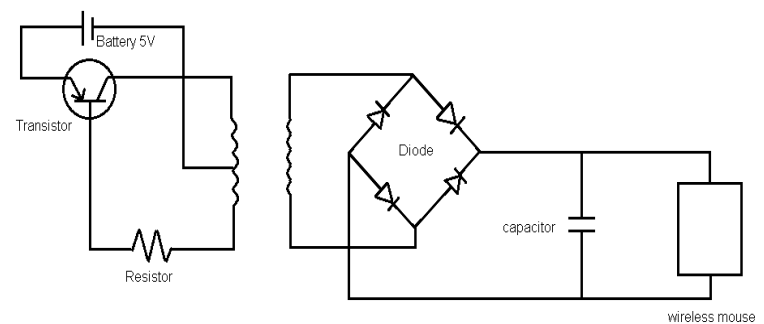

Figure 10: Schematic diagram of full circuit WPT

The full circuit of WPT shown in Figure 10 tends to be test by using the breadboard to check the functionality of the inverter and rectifier circuit designs before the components will solder on the PCB. Figure 11 shows the circuit of WPT for mouse application have been testing on the breadboard.

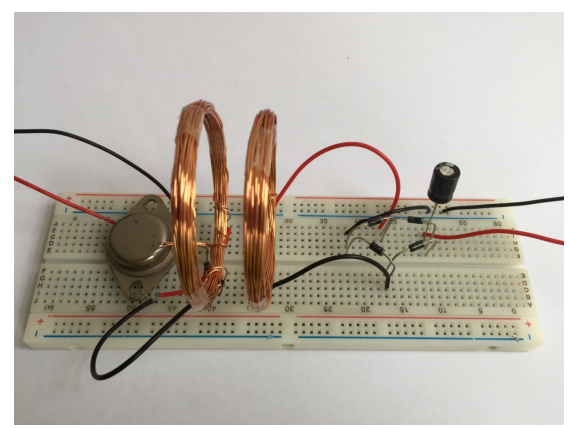

Figure 11: Full circuit tested on the breadboard

The copper coil are used as transmitter and receiver coil for the data analysis in term of output voltage of $1 \mathrm{~cm}$ distance and also maximum distance of $1.5 \mathrm{~V}$ output voltages for the performance efficiency of WPT. The length of copper wire needed for each of the copper coil is measured and tabulated in the Table 1 by using the formula as below,

$$
\mathrm{C}=2 \times \pi \times \mathrm{r}
$$

Where;

$$
\begin{aligned}
& \pi=3.14 \\
& r \quad=\text { Radius of the copper coil }
\end{aligned}
$$

Then, determine the optimal power transfer distance and the output voltage between the two coils. Figure 12 illustrates the circuit diagram for WPT system using IPT concept for mouse application. This circuit was simulating by using Proteus software. In the transmitter side, it has three components which are battery, transistor and resistor. For the B1, it is the battery of $5 \mathrm{~V}$ DC to supply the power. The battery used in this 
simulation actually as the replacement of the actual power supply. The power supply in this project connected from the USB port laptop. Basically, the USB port laptop supplies $5 \mathrm{~V}$ DC so that why the battery of $5 \mathrm{~V}$ DC has been chosen in this simulation as the power supply. Next, Q1 as the transistor which type MJ2955 used to amplify or switch electronic signals and electrical power. For the R1, it indicates as the resistor which values is $68 \mathrm{ohm}$.

Next, in the receiver side, it has three components which are diodes, capacitor and Light Emitting Diode (LED). For the D1, D2, D3 and D4, it acts as the diode which type 1N4007 used in the circuit. This diodes function as the bridge rectifier to convert the AC voltage from the receiver coil to the $\mathrm{DC}$ voltage. $\mathrm{C} 1$ as the capacitor and the value for the capacitor used in this circuit is $470 \mathrm{~F}$. The function of capacitor is to smooth the current flow from the bridge rectifier to the load. The last component is LED as the electrical load which the value of voltage is set to $1.5 \mathrm{~V}$ and the current is $20 \mathrm{~mA}$. It is because the LED was used as the replacement for the wireless mouse to test the circuit simulation. To power up the wireless mouse, the input voltage and current is $1.5 \mathrm{~V}$ and $20 \mathrm{~mA}$. So, the LED has been chosen as the electrical load.

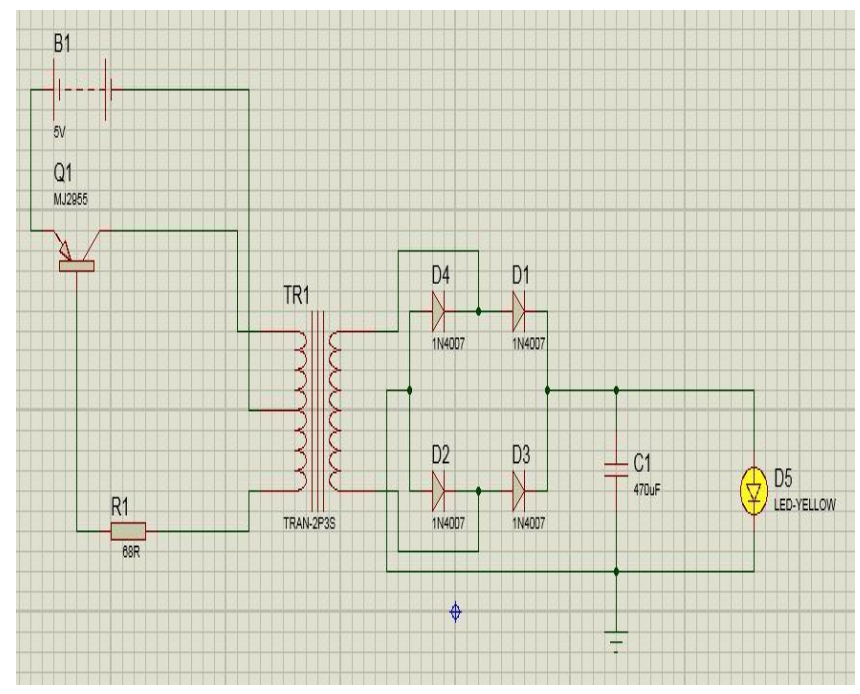

Figure 12: Circuit diagram for WPT

Figure 13 shows the prototype design of the WPT system for mouse application along with the label of the components that is installed.

\section{RESULTS}

By using the receiver coil in which its diameter is bigger than the transmitter coil it will affected the distance of voltage transfer. In other words, when the receiver coil is bigger than the transmitter coil in term of size of diameter and number of turns of the coil, the amount of voltage that can be transfer is bigger than the using of smaller diameter of receiver coil but the distance will be shorter between transmitter coil and receiver coil. In addition, when using the transmitter coil in which its diameter and number of turns of the coil is bigger than the receiver coil it can transfer with higher voltage and also the distance will be longer. According to [22], to further indefinite quantity of Power Transfer Efficiency (PTE), basically it should enlarge the diameter of coils [22]. This effect can be view by the comparison as shown in Figure 14 and Figure 15.

Table 1: Length of copper wire for each copper coil

\begin{tabular}{|c|c|c|c|c|c|}
\hline \multicolumn{3}{|c|}{ Transmitter Coil } & \multicolumn{3}{c|}{ Receiver Coil } \\
\hline $\begin{array}{c}\text { Diamet } \\
\text { er of } \\
\text { Coil, } \\
\text { cm }\end{array}$ & $\begin{array}{c}\text { Numbe } \\
\text { r of } \\
\text { Turns, } \\
\text { N }\end{array}$ & $\begin{array}{c}\text { Length } \\
\text { of } \\
\text { Copper } \\
\text { wire, } \\
\text { cm }\end{array}$ & $\begin{array}{c}\text { Diamet } \\
\text { er of } \\
\text { Coil, } \\
\text { cm }\end{array}$ & $\begin{array}{c}\text { Numbe } \\
\text { r of } \\
\text { Turns, } \\
\text { N }\end{array}$ & $\begin{array}{c}\text { Length } \\
\text { of } \\
\text { Copper } \\
\text { wire, } \\
\text { cm }\end{array}$ \\
\hline 6 & 26 & 490.1 & 5.5 & 25 & 431.97 \\
\hline 5.5 & 22 & 380.13 & 5 & 30 & 471.24 \\
\hline 5 & 30 & 471.24 & 4.5 & 22 & 311.02 \\
\hline 4.5 & 28 & 395.84 & 4 & 28 & 351.86 \\
\hline 4 & 36 & 452.39 & 3.5 & 32 & 351.86 \\
\hline \multicolumn{2}{|c|}{ Total Length of } & 2189.7 & \multicolumn{3}{|c|}{$\begin{array}{c}\text { Total Length of } \\
\text { Copper wire, cm }\end{array}$} \\
\hline \multicolumn{4}{|c|}{ Copper wire, cm } & & \multicolumn{4}{|c|}{1917.95} \\
\hline
\end{tabular}

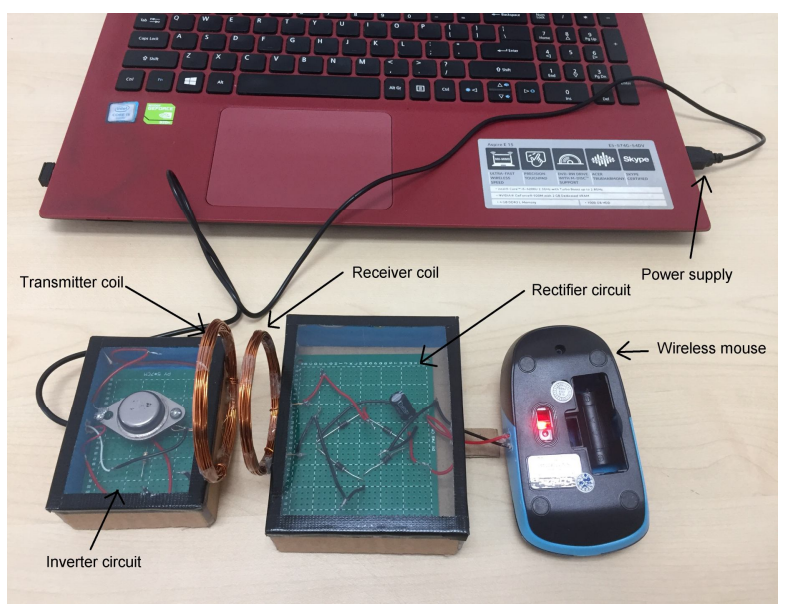

Figure 13: Prototype design of WPT system 


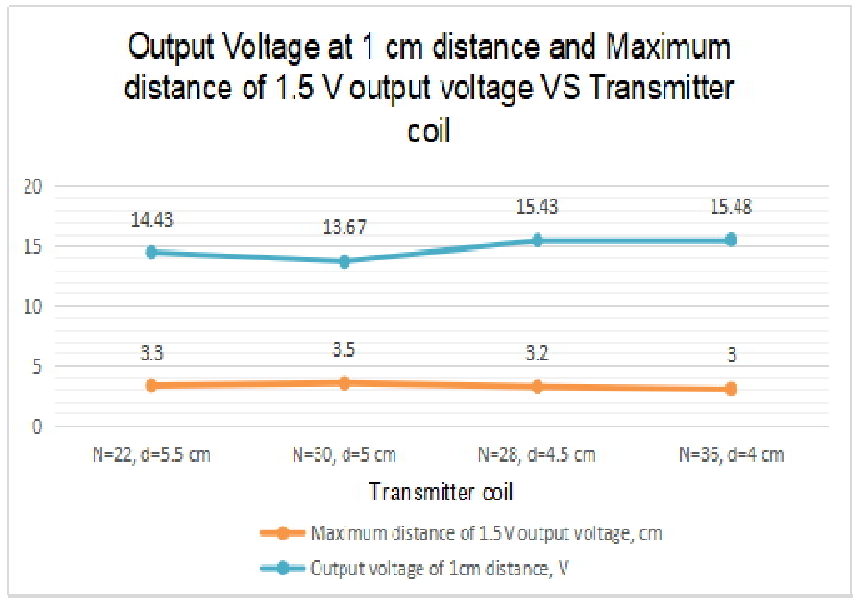

Figure 14: Output voltage and maximum distance VS transmitter coil

Based on Figure 14 the receiver coil was fixed to the $(\mathrm{N}=25, \mathrm{~d}=5.5 \mathrm{~cm})$ where diameter bigger than the transmitter coil diameter.

\section{Output Voltage at $1 \mathrm{~cm}$ distance and Maximum distance of 1.5 V output voltage VS Transmitter \\ coil}

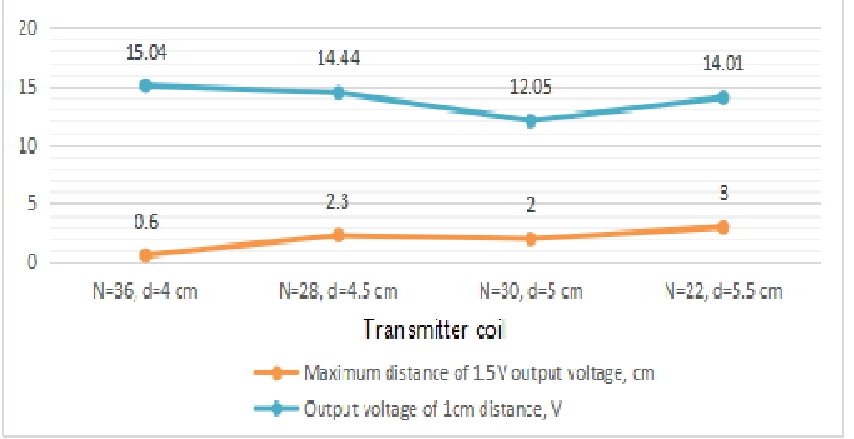

Figure 15: Output voltage and maximum distance VS transmitter coil

Based on Figure 15, the receiver coil was fixed to the $(\mathrm{N}=32$, $\mathrm{d}=3.5 \mathrm{~cm}$ ) where diameter smaller than the transmitter coil diameter.

From Figure 14 and Figure 15, both graphs shows the analysis of coils design which is transmitter coil smaller than receiver coil and also transmitter coil bigger than receiver coil. Based on observation from Figure 14, it can be said that when the number or diameter of turns at transmitter are smaller than the number or diameter of turns at receiver, then the output voltage are increased but the distance are decreased. For Figure 15, when the number or diameter of turns at transmitter are bigger than the number or diameter of turns at receiver, then the output voltage are increased and also the distance are increased. This observation can conclude as shown on Table 2 .
Table 2: Relationship between sizes of coil to the output Voltage and Distance

\begin{tabular}{|c|c|c|c|}
\hline $\begin{array}{c}\text { Transmitter } \\
\text { Coil }\end{array}$ & $\begin{array}{c}\text { Receiver } \\
\text { Coil }\end{array}$ & $\begin{array}{c}\text { Output } \\
\text { Voltage }\end{array}$ & Distance \\
\hline Smaller & Bigger & Increase & Decrease \\
\hline Bigger & Smaller & Increase & Increase \\
\hline
\end{tabular}

As a conclusion, the number of turns or diameter of coils is directly proportional with the distance and also the output voltage. When the input voltage at Tx coil is increased, the output voltage obtain at Rx coil also will increased. To increase the efficiency of WPT, It must be considered in term of coils design so that the power can transfer farther wirelessly between the two coils.

\section{CONCLUSION}

The WPT is one of the green technology approach because it save the environment and also to the human health from the e-waste which is alkaline battery. By doing this project it can eliminate the usage of battery and just used the concept of WPT to powered up the load.

Next, the WPT give a lot of benefits in the future in terms of the application and safety to the environment and also human being. The WPT is needed in the future for the rapid development and high density population so that it can replace the used of wire as medium of transmitting the energy with WPT. Based on the data analysis that have been done, it shows that the bigger the transmitter coil than the receiver coil the higher output voltage generated and the longer distance can be transfer wirelessly between two coils. Besides, this prototype can be transfer wirelessly from transmitter coil to the receiver coil to power up the wireless mouse which the output voltage of $1 \mathrm{~cm}$ distance is $12.6 \mathrm{~V}$ and the maximum distance of $1.5 \mathrm{~V}$ output voltages that can be transfer is 4.5 $\mathrm{cm}$.

\section{REFERENCES}

1. M. El Rayes, M., Nagib, G., \& G. Ali Abdelaal, W. (2016). A Review on Wireless Power Transfer. International Journal of Engineering Trends and Technology, (5), 272-280. https://doi.org/10.14445/22315381/IJETT-V40P244

2. Asri, M., Abidin, Z., Ibrahim, W. I., \& Jadin, M. S. (2015). Design of Inductive Power Transfer for Low Power Application, ARPN Journal of Engineering and Applied Sciences, 10(21), 9807-9812.

3. Zain, Z. M., Ismail, A. F., \& Bahisham, S. (2014). Development of a Resonant Inductive Coupling Wireless Battery Charger, International Conference Recent treads in Engineering \& Technology 
(ICRET’2014) Feb 13-14, 2014 Batam (Indonesia), pp. 36-38.

4. Pawade, S., Nimje, T., \& Diwase, D. (2012). Goodbye Wires: Approach to Wireless Power Transmission, International Journal of Emerging Technology and Advanced Engineering, 2(4), 382-387.

5. Anthony, R. N., \& Navghare, S. P. (2016). Introduction To Wireless Power Transfer, International Journal of Scientific Engineering and Applied Science, 2(1), 195-196.

6. Liguang, Y. S., Y. T. Hou, Wenjing L. (2013). Wireless power transfer and applications to sensor networks, IEEE Wireless Communications, 20(4),140-145. https://doi.org/10.1109/MWC.2013.6590061

7. Maqsood, M., \& Nasir, M. N. (2013). Wireless electricity (Power) transmission using solar based power satellite technology. Journal of Physics: Conference Series, 439, 012046.

8. Sharma, A. (2014). Application of Wireless Power Transfer for Home Appliances using Inductive Resonance Coupling. International Journal of Engineering Trends and Technology, 16(4), 159-163.

9. Shidujaman, M., Samani, H., \& Arif, M. (2014). Wireless power transmission trends. 2014 International Conference on Informatics, Electronics \& Vision (ICIEV), (May), 1-6.

10. L. R. Clare, S. G. Burrow, B. H. Stark, N. J. Grabham, S. P. Beepy (2015). Design of an Inductive Power Transfer System with Flexible Coils for Body-worn Applications. J. Phys.: Conf. Ser. 660, 012135.

11. Silva, G. G. da, \& Petry, C. A. (2015). Capacitive Wireless Power Transfer System Applied to Low-Power Mobile Device Charging. International Journal of Electrical Energy, 3(4), 230-234.

12. Xia, C., Zhou, Y., Zhang, J., \& Li, C. (2012). Comparison of power transfer characteristics between CPT and IPT system and mutual inductance optimization for IPT system. Journal of Computers (Finland), 7(11), 2734-2741. https://doi.org/10.4304/jcp.7.11.2734-2741

13. M Fareq, M. F., Irwanto, Syafruddin H., M. A. (2014). Low wireless power transfer using Inductive Coupling for mobile phone charger. Journal of Physics Ser, 495, 012019.

14. Johns, B., Siddabattula, K., \& Sengupta, U. (2014). Adapting Qi-compliant wireless-power solutions to low-power wearable products. Analog Applications Journal, 14-18.

15. Bill Johns, Tony Antonacci, K. S. (2012). Designing a Qi-compliant Qi receiver coil for wireless power systems, Part 1. Texas Instruments Incorporated, 1, 8-14.

16. Wang, H. (2016). Multiple-Resonator Wireless Power Transmission System Design and Integrated Data Path. Doctoral Dissertation, University of Pittsburgh.

17. Vijayakumaran Nair, V., \& Choi, J. R. (2016). An efficiency enhancement technique for a wireless power transmission system based on a multiple coil switching technique. Energies, 9(3), 156.

18. A. P., Meyer, D. A., \& Smith, J. R. (2011). Analysis, experimental results, and range adaptation of magnetically coupled resonators for wireless power transfer. IEEE Transactions on Industrial Electronics, 58(2), 544-554.

19. Hui, S. Y. R., Zhong, W., \& Lee, C. K. (2014). A critical review of recent progress in mid-range wireless power transfer. IEEE Transactions on Power Electronics, 29(9), 4500-4511. https://doi.org/10.1109/TPEL.2013.2249670

20. Liang, S. P. (1977). Design of radio-frequency powered coils for implant instruments, Medical and Biological Engineering and Computing, 15(6),1976-1977.

21. Harrison, R. R. (2007). Designing Efficient Inductive Power Links for Implantable Devices, IEEE International Symposium on Circuits and Systems, New Orleans, LA, 2007, 2080-2083. https://doi.org/10.1109/ISCAS.2007.378508

22. Mehdi Kiani, Uei-Ming Jow, Maysam Ghovanloo (2011). Design and Optimization of a 3-Coil Inductive Link for Efficient Wireless Power Transmission, IEEE Transactions on Biomedical Circuits and Systems, 5(6), 579-591. https://doi.org/10.1109/TBCAS.2011.2158431 